\title{
GAMBARAN TUMPATAN RESIN KOMPOSIT PADA GIGI PERMANEN DI POLIKLINIK GIGI RUMKITAL DR. WAHYU SLAMET
}

\author{
${ }^{1}$ Devistha M. P. Tulenan \\ ${ }^{2}$ Dinar A. Wicaksono \\ ${ }^{2}$ Joenda S. Soewantoro
}

\author{
${ }^{1}$ Kandidat Skripsi Program Studi Pendidikan Dokter Gigi Fakultas Kedokteran \\ Universitas Sam Ratulangi \\ ${ }^{2}$ Program Studi Pendidikan Dokter Gigi Fakultas Kedokteran Universitas Sam Ratulangi \\ Email:devi.tulenan@gmail.com
}

\begin{abstract}
Abstrak: Karies gigi merupakan penyakit jaringan keras gigi yang sering dialami oleh setiap individu. Salah satu penyebab karies gigi yaitu karena kurangnya kesadaran masyarakat akan kesehatan gigi dan mulut. Perawatan yang diberikan untuk gigi yang karies ialah penumpatan dan resin komposit pada pasien sering dipilih dokter gigi di Poliklinik Gigi RUMKITAL dr. Wahyu Slamet sebagai bahan tumpatan. Jenis penelitian ini merupakan penelitian deskriptif, penelitian ini bertujuan untuk mengetahui gambaran tumpatan resin komposit pada gigi permanen sebagai bahan tumpatan gigi di Poliklinik Gigi RUMKITAL dr. Wahyu Slamet pada tahun 2012-2013. Sampel pada penelitian ini ialah rekam medik pasien yang giginya ditumpat resin komposit. Jumlah sampel penelitian yang diambil yaitu 222 pasien dengan 319 gigi yang ditumpat dan dikategorikan berdasarkan tahun penumpatan, jenis kelamin, umur pasien, pekerjaan pasien, jumlah gigi dan regio gigi. Hasil penelitian menunjukkan berdasarkan tahun penumpatan, penggunaan tumpatan resin komposit pada gigi permanen pada tahun 2013 paling banyak digunakan yaitu sebanyak 113 tumpatan (50,9\%) sedangkan pada tahun 2012 berjumlah 109 tumpatan (49,1\%). Perawatan dengan resin komposit paling banyak juga dilakukan oleh pasien yang berjenis kelamin laki-laki sebanyak 122 orang (55,0\%) daripada penggunaan tumpatan resin komposit pada pasien berjenis kelamin perempuan yang berjumlah 100 orang (45,0\%). Berdasarkan golongan umur menunjukkan penggunaan tumpatan resin komposit terbanyak pada golongan umur 26-55 tahun sebanyak 138 orang (62,2\%). Berdasarkan pekerjaan, tumpatan resin komposit paling banyak pada pelajar yang berjumlah 63 orang (28,4\%). regio gigi posterior yang berjumlah 244 tumpatan (76,5\%) merupakan regio gigi yang paling banyak mendapatkan tumpatan resin komposit dan setiap pasien lebih banyak melakukan tumpatan resin komposit pada 1 gigi yang berjumlah 146 orang (65,8\%).
\end{abstract}

Kata kunci: resin komposit, penumpatan.

\begin{abstract}
Teeth caries is a disease of teeth hard net suffered by every individual. One of the causes of caries is peoples' lack of awareness teeth and mouth health. Filling and the composite resin as the component of filling is the treatment often used by dentist in RUMKITAL Teeth Policlinic, dr. Wahyu Slamet. This study aims to find out the composite resin as component of fillings on permanent teeth at dr. Wahyu Slamet' s RUMKITAL Teeth Policlinic in 2012-2013. This study is a descriptive study. The sample of the study are patients of medical record whose teeth have been clogged up with the composite resin. The number of the taken sample are 222 patients with 319 clogged up teeth and are categorized based on the filling year, gender, age, job, number of teeth, and teeth regio. The result shows that based on the year of fllling, the composite resin filling are used on permanent teeth mostly n 2013, that is 113 fillings (50,9\%), while in 2012 are 109 fillings (49,1\%). Treatment with resin composite are mostly used on male patients, which are 122 patients (55,9\%), while the use of composite resin fillings on female are 100 pasients (45,0\%). Be based on the age group, the resin composite fillings are mostly used patients age between 26-55 years, which are 138 patients (62,2\%). Be based on job, composite resin filling is mostly used on students, which are 63 patients (28,4\%). Posterior teeth region which amount to 244 filling (76,5\%) are the teeth region having most composite resin fillings and most of the patient do the composite resin fillings on 1 tooth, which are 146 people $(65,8 \%)$.
\end{abstract}

Keywords: composite resin, filling. 
Kesehatan gigi dan mulut merupakan bagian dari kesehatan tubuh yang tidak dapat dipisahkan satu dan lainnya karena akan mempengaruhi kesehatan tubuh keseluruhan. Gigi merupakan salah satu bagian tubuh yang berfungsi untuk mengunyah, berbicara dan mempertahankan bentuk muka, sehingga penting untuk menjaga kesehatan gigi sedini mungkin agar dapat bertahan lama dalam rongga mulut. ${ }^{1}$

Masalah terbesar yang dihadapi penduduk Indonesia seperti juga di negaranegara berkembang lainnya di bidang kesehatan gigi dan mulut adalah penyakit jaringan keras gigi. Menurut Data Riset Kesehatan Dasar (Rikesdas) dari Kementrian Kesehatan Republik Indonesia pada tahun 2013 menunjukan indeks DMF$\mathrm{T}$ sebesar 4,6 dengan nilai masing-masing $\mathrm{D}-\mathrm{T}=1,6, \mathrm{M}-\mathrm{T}=2,9, \mathrm{~F}-\mathrm{T}=0,08$, dan indeks DMF-T di provinsi Sulawesi Utara sebesar 5,4 dengan nilai masing-masing $\mathrm{D}-\mathrm{T}=1,9$, $\mathrm{M}-\mathrm{T}=3,4$, dan $\mathrm{F}-\mathrm{T}=0,06$. $^{2}$

Karies gigi adalah suatu proses kerusakan yang dimulai dari email terus ke dentin dan merupakan suatu penyakit yang berhubungan dengan banyak faktor. Ada empat faktor utama yang saling mempengaruhi untuk terjadinya karies yaitu faktor host yang meliputi gigi dan saliva, faktor kedua ialah mikroorganisme, ketiga adalah substrat dan keempat adalah waktu. ${ }^{1}$

Salah satu perawatan karies gigi ialah dengan melakukan penumpatan. Penumpatan yaitu suatu tindakan perawatan dengan meletakkan bahan tumpatan pada karies gigi yang sudah dibersihkan. Perawatan karies gigi tergantung pada seberapa besar tingkat kerusakan gigi. Bahan tumpatan yang digunakan bermacammacam, misalnya resin komposit, semen ionomer kaca, kompomer, dan amalgam. ${ }^{3}$

Resin komposit adalah suatu material yang terbentuk dari kombinasi antara dua bahan atau lebih yang memiliki sifat berbeda untuk mendapatkan sifat yang lebih baik. Resin komposit merupakan bahan adhesif yang dapat berikatan dengan jaringan keras gigi melalui dua system bonding (ikatan) yaitu ikatan email dan ikatan dentin. Bahan restorasi resin komposit pada bidang kedokteran gigi dimulai pada awal 1960, ketika Bowen memulai percobaan untuk memperkuat resin epoksi dengan partikel bahan pengisi. Pada perkembangannya, bahan resin komposit modern mengandung sejumlah komponen untuk mendapatkan sifat-sifat yang lebih baik sehingga memenuhi sifat ideal untuk suatu tumpatan. ${ }^{4,5}$

Resin komposit sering digunakan sebagai bahan tumpatan di kedokteran gigi. Kandungan utama resin komposit terdiri atas matriks resin dan bahan pengisi. Dimasukannya partikel bahan pengisi kedalam suatu matriks secara nyata meningkatkan sifat bahan matriks bila partikel pengisi benar-benar berikatan dengan matriks, Coupling Agent merupakan bahan yang di gunakan untuk memberikan ikatan antara partikel bahan pengisi anorganik dengan matriks resin, penghambat polimerisasi merupakan penghambat bagi terjadinya polimeralisasi dini, opasitas ialah warna yang visual dan transluensi yang dapat menyesuaikan dengan warna email dan dentin harus di miliki oleh resin komposit, dan pigmen warna bertujuan agar warna resin komposit menyerupai warna gigi geligi asli. ${ }^{5}$

Klasifikasi Resin komposit berdasakan ukuran partikel bahan pengisi yaitu (Tabel 1): ${ }^{6}$

Tabel 1. Klasifikasi Resin Komposit ${ }^{7}$

\begin{tabular}{ll}
\hline Kategori & $\begin{array}{l}\text { Ukuran Partikel } \\
(\boldsymbol{\mu m})\end{array}$ \\
\hline Komposit Tradisional & $8-12$ \\
Komposit Berbahan & $1-5$ \\
Pengisi Mikro & \\
Komposit Partikel Kecil & $0,04-0,4$ \\
Komposit Hybrid & $0,6-1,0$ \\
Komposit Nano Hybrid & $0,00-0,1$ \\
\hline
\end{tabular}

Resin komposit merupakan bahan tumpatan gigi yang banyak digunakan untuk menggantikan struktur gigi yang hilang serta memodifikasi warna dan kontur gigi dengan tujuan estetik (Gambar 1). ${ }^{8}$ 


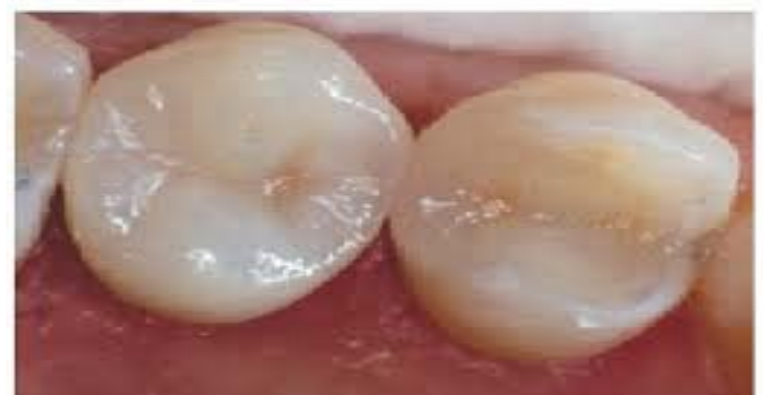

Gambar 1. Tumpatan komposit. ${ }^{9}$

Pada penggunaan resin komposit diharapkan dapat bertahan selama mungkin dalam mulut. Adapun indikasi dan kontraindikasi dalam penggunaan komposit yaitu sebagai sealant pada restorasi resin preventif untuk mencegah terjadinya karies pada daerah cekungan yang dalam dan sempit. Kontraindikasi penggunaan resin komposit yaitu tekanan pengunyahan yang besar, pasien dengan insidensi karies tinggi,dan pasien yang sensitivitas terhadap material komposit. ${ }^{10,11}$

Dalam penggunaannya sebagai bahan tumpatan, resin komposit memiliki kekurangan dan kelebihan yaitu bahannya tidak berbahaya/tidak mengandung merkuri, dapat dipergunakan pada gigi posterior, warna resin komposit yang sewarna dengan gigi, dan sifat mekanik dan fisik cukup baik, dan preparasi dapat dilakukan dalam 1 kali kunjungan' Kekurangan resin komposit yaitu bahan ini dapat berubah warna saat pemakaian jangka panjang, terjadi pengerutan saat polimeralisasi, biayanya relatif mahal, membutuhkan waktu lebih lama, dan keausan permukaan oklusal yang signifikan. ${ }^{12,13,14}$

Kota Bitung merupakan salah satu wilayah di provinsi Sulawesi Utara yang sedang berkembang dari segi ekonomi dan sosial. Hal ini juga tergambar dari pelaksanaan perawatan kesehatan gigi dan mulut, salah satunya di Rumah Sakit Angkatan Laut (RUMKITAL) dr. Wahyu Slamet. RUMKITAL dr. Wahyu Slamet ialah salah satu rumah sakit yang berlokasi di kota Bitung dimana poliklinik giginya memiliki tenaga medis spesialis di bidang konservasi gigi. Dengan adanya tenaga spesialis ini maka poliklinik gigi rumah sakit angkatan laut menjadi salah satu rumah sakit yang memiliki pelayanan konservasi gigi terbaik. Poliklinik gigi RUMKITAL dr. Wahyu Slamet sudah jarang menggunakan amalgam sebagai bahan restorasi gigi karena bahan restorasi tersebut mengandung merkuri yang tidak baik bagi kesehatan manusia. Perawatan yang sering dilakukan dalam penumpatan dengan menggunakan komposit.

Berdasarkan uraian di atas peneliti mengambil judul “Tumpatan Resin Komposit Pada Gigi Permanen di Poliklinik Gigi RUMKITAL dr. Wahyu Slamet Bitung”.

\section{METODE PENELITIAN}

Penelitian ini merupakan jenis penelitian deskriptif, yang berlangsung selama bulan Juni-Agustus tahun 2014 di RUMKITAL dr. Wahyu Slamet. RUMKITAL dr. wahyu Slamet merupakan instansi milik TNI Angkatan Laut tingkat III daerah Sulawesi Utara yang bergerak dalam kesehatan di kota Bitung yang berlokasi di Jalan Yos Sudarso No.26 Kecamatan Maesa, Kelurahan Bitung Barat Dua kota Bitung. Metode pengambilan sampel yang digunakan ialah metode total sampling. Populasi dalam penelitian ini ialah rekam medis pasien yang giginya telah ditumpat resin komposit di poliklinik gigi RUMKITAL dr. Wahyu Slamet dari januari tahun 2012 sampai dengan desember tahun 2013.Alat dan bahan yang di gunakan ialah format isian rekam medis dan alat tulis menulis.

\section{HASIL PENELITIAN}

Pada penelitian ini data dikumpulkan berdasarkan tahun penumpatan, jenis kelamin, umur, pekerjaan, jumlah gigi, dan regio gigi.

Tabel 2. Distribusi frekuensi tumpatan resin komposit berdasarkan tahun penumpatan

\begin{tabular}{ccc}
\hline \multirow{2}{*}{ Tahun Penumpatan } & \multicolumn{2}{c}{ Tumpatan resin komposit } \\
\cline { 2 - 3 } & $\mathrm{n}$ & $\%$ \\
\hline 2012 & 109 & 49,1 \\
2013 & 113 & 50,9 \\
Total & 222 & 100 \\
\hline
\end{tabular}


Jurnal e-GiGi (eG), Volume 2, Nomor 2, Juli-Desember 2014

Tabel 3. Distribusi frekuensi tumpatan resin komposit berdasarkan jenis kelamin

\begin{tabular}{ccc}
\hline \multirow{2}{*}{ Jenis Kelamin } & \multicolumn{2}{c}{ Tumpatan resin komposit } \\
\cline { 2 - 3 } & $\mathrm{n}$ & $\%$ \\
\hline Laki-laki & 122 & 55,0 \\
Perempuan & 100 & 45,0 \\
Total & 222 & 100 \\
\hline
\end{tabular}

Tabel 4. Distribusi frekuensi tumpatan resin komposit berdasarkan umur

\begin{tabular}{ccc}
\hline \multirow{2}{*}{ Umur } & \multicolumn{2}{c}{ Tumpatan resin komposit } \\
\cline { 2 - 3 } & $\mathrm{n}$ & $\%$ \\
\hline$<10$ tahun & 4 & 1,7 \\
$11-25$ tahun & 73 & 32,9 \\
$26-55$ tahun & 138 & 62,2 \\
$>60$ tahun & 7 & 3,2 \\
Total & 222 & 100 \\
\hline
\end{tabular}

Tabel 5. Distribusi frekuensi tumpatan resin komposit berdasarkan pekerjaan

\begin{tabular}{ccc}
\hline \multirow{2}{*}{ Pekerjaan } & \multicolumn{2}{c}{ Tumpatan resin komposit } \\
\cline { 2 - 3 } & $\mathrm{n}$ & $\%$ \\
\hline TNI AL & 51 & 23,0 \\
PNS & 39 & 17,6 \\
Wiraswasta & 40 & 18,0 \\
& 8 & 3,6 \\
Guru & 4 & 1,7 \\
Pensiunan & 17 & 7,7 \\
Ibu Rumah Tangga & 63 & 28,4 \\
Pelajar & 222 & 100 \\
Total & & \\
\hline
\end{tabular}

Tabel 6. Distribusi frekuensi resin komposit berdasarkan jumlah gigi yang ditumpat

\begin{tabular}{ccc}
\hline $\begin{array}{c}\text { Jumlah gigi yang } \\
\text { ditumpat dalam 1 } \\
\text { rongga mulut }\end{array}$ & \multicolumn{2}{c}{ Tumpatan resin komposit } \\
\cline { 2 - 3 } & $\mathrm{n}$ & $\%$ \\
\hline 1 & 146 & 65,8 \\
3 & 61 & 27,5 \\
4 & 10 & 4,5 \\
5 & 4 & 1,7 \\
Total & 1 & 0,5 \\
\hline
\end{tabular}

\section{BAHASAN}

Berdasarkan tahun penumpatan, tumpatan resin komposit pada gigi permanen menunjukkan pada tahun 2013 berjumlah 113 tumpatan (50,9\%) dan pada
Tabel 7. Distribusi frekuensi resin komposit berdasarkan regio gigi

\begin{tabular}{lcc}
\hline \multirow{2}{*}{ Regio gigi } & \multicolumn{2}{c}{ Tumpatan resin komposit } \\
\cline { 2 - 3 } & $\mathrm{n}$ & $\%$ \\
\hline Anterior Rahang Atas & 74 & 23,2 \\
Posterior Rahang atas & 97 & 30,4 \\
Anterior Rahang & 1 & 0,3 \\
Bawah & 147 & 46,1 \\
Posterior Rahang & 319 & 100 \\
Bawah & & \\
\multicolumn{1}{c}{ Total } & & \\
\hline
\end{tabular}

tahun 2012 berjumlah 109 tumpatan (49,1\%). Distribusi ini menunjukkan bahwa semakin banyak masyarakat yang menyadari pentingnya kesehatan gigi dan mulut, sehingga penggunaan resin komposit semakin banyak dari tahun ke tahun. Terlebih lagi teknologi komposit yang terus mengalami perkembangan dan modifikasi yang meningkatkan kelebihan resin komposit secara fisik, mekanik dan biologis. Salah satu perkembangan resin komposit yang terbaik saat ini adalah resin komposit nano hybrid yang memiliki kemampuan penanganan dan kemampuan polish didapat dari resin komposit berbahan pengisi mikro serta kekuatan dan ketahanan pemakaian dari resin komposit berbahan pengisi makro, sehingga resin komposit nano hybrid dapat digunakan sebagai restorasi pada gigi anterior maupun posterior. ${ }^{15}$

Distribusi berdasarkan jenis kelamin penggunaan resin komposit pada RUMKITAL dr. Wahyu Slamet pasien lakilaki merupakan kelompok yang paling banyak mendapatkan perawatan tumpatan resin komposit yaitu sebanyak 122 orang (55,0\%) dan tumpatan resin komposit pada pasien berjenis kelamin perempuan yaitu 100 orang (45,0\%). Hasil ini berbeda dengan penelitian sebelumnya yang dilakukan di Rumah Sakit Gigi dan Mulut Pendidikan (RSGMP) Fakultas Kedokteran Gigi Universitas Indonesia, dimana pasien perempuan $(62,3 \%)$ merupakan pasien yang paling banyak melakukaan perawatan tumpatan resin komposit daripada laki-laki $(37,7 \%){ }^{16}$ 
Tulenan, Wicaksono, Soewantoro; Gambaran Tumpatan Resin Komposit...

Dalam penelitian ini didapatkan hasil laki-laki memiliki jumlah lebih banyak daripada kaum perempuan dalam penggunaan bahan tumpatan komposit dikarenakan pasien yang datang dan melakukan perawatan di poliklinik gigi RUMKITAL dr. Wahyu Slamet sebagian besar berjenis kelamin laki-laki dan juga pada RUMKITAL dr. wahyu slamet merupakan rumah sakit yang berada di bawah naungan angkatan laut yang anggotanya didominasi oleh laki-laki. Selain itu dalam kegiatan militer angkatan laut tumpatan sangatlah penting untuk menunjang pekerjaan anggota militer angkatan laut yang salah satu kegiatan pokoknya adalah penyelaman. Dalam ilmu kesehatan penyelaman setiap rongga dalam mulut akan menyebabkan suatu kecelakaan dalam penyelaman yang disebut barotrauma, jika karies tidak ditangani akan berbahaya. Oleh karena itu salah satu perawatan karies gigi ialah penumpatan dengan menggunakan resin komposit. ${ }^{17}$

Berdasarkan penelitian yang dilakukan menunjukkan bahwa golongan umur 26-55 tahun merupakan yang paling banyak melakukan tumpatan resin komposit sebanyak 138 orang (62,2\%) sedangkan pada golongan umur $>60$ tahun penggunaan resin kompositnya sebanyak 7 orang (3,2\%). Hal ini sejalan dengan penelitian yang dilakukan oleh Sajow tentang gambaran penggunaan bahan restorasi resin komposit di Rumah Sakit Gigi dan Mulut (RSGM) Universitas Sam Ratulangi tahun 2011-2012 yang menyatakan bahwa pasien yang berumur dewasa berjumlah $47,5 \%{ }^{18}$

Dari hasil penelitian diketahui bahwa kelompok usia yang paling banyak melakukan perawatan restorasi gigi ialah golongan umur dewasa (26-55 tahun), daripada golongan umur lainnya. Hal ini diperkirakan karena umur dewasa telah memilik pengetahuan dan kesadaran diri yang tinggi terhadap segi estetika dan fungsional dari kesehatan gigi dan mulutnya. Bila mana pasien dewasa mengalami sakit gigi atau gigi berlubang, pasien dewasa akan segera berobat ke dokter gigi untuk dilakukan penumpatan, agar proses keparahan penyakit dapat dihentikan dan juga pada golongan umur $>60$ tahun kebanyakkan pasien sudah tidak lagi memiliki gigi yang utuh atau sudah banyak yang ompong sehingga kebanyakan pasien menggunakan gigi palsu.

Berdasarkan jenis pekerjaan menunjukan bahwa pasien dengan pekerjaan sebagai pelajar merupakan kelompok paling banyak menerima perawatan tumpatan komposit yaitu sebanyak 63 orang $(28,4 \%)$ dan pada pekerjaan TNI AL sebanyak 51 orang (23\%). Hal ini sejalan dengan penelitian yang dilakukan oleh Sajow tentang gambaran penggunaan bahan restorasi resin komposit di RSGM Unversitas Sam Ratulangi tahun 2011-2012 yang menyatakan bahwa pelajar adalah kelompok yang paling banyak mendapatkan perawatan restorasi resin komposit sebanyak $75 \%$ dari total 85 pasien. $^{18}$

Dari hasil penelitian diketahui bahwa kelompok umur yang paling banyak melakukan perawatan restorasi gigi yaitu kelompok pekerjaan pelajar, hal ini disebabkan karena sebagian pelajar mempunyai orangtua yang bekerja di angkatan laut sehingga para pelajar mendapatkan pelayanan gratis, dan juga di RUMKITAL dr. Wahyu Slamet menyediakan pelayanan drg. spesialis dengan harga terjangkau bahkan gratis melalui program BPJS, ASKES, JAMSOSTEK, JAMKESMAS, serta ada juga sebagian mahasiswa AMI (Akademik Maritim Indonesia) Bitung yang melakukan perawatan kesehatan gigi di RUMKITAL dr. Wahyu Slamet yang dimana apabila mereka menunjukan kartu anggota maka mereka akan mendapat pelayanan gratis karena adanya kerja sama antara AMI Bitung dan RUMKITAL dr. Wahyu Slamet.

Dari hasil penelitian, minimal terdapat satu gigi pada setiap pasien yang mendapatkan perawatan tumpatan dengan resin komposit yaitu sebesar 65,8\% dari 319 jumlah gigi yang ditumpat. Sedangkan untuk dua gigi pada setiap pasien yaitu sebesar $27,5 \%$, tiga gigi sebesar $4,5 \%$, empat gigi sebesar $1,7 \%$ dan 5 gigi sebesar $0,5 \%$. 
Hal ini sejalan dengan hasil penelitian yang dilakukan oleh Surentu di RS Advent Manado yang menyatakan bahwa terdapat satu gigi pada setiap pasien yang mendapatkan perawatan tumpatan resin komposit yaitu sebesar 54,5\%. Sedangkan untuk dua gigi pada setiap pasien yaitu sebesar 29,5\%, tiga gigi sebesar 9,5\%, empat gigi sebesar 3,1\% dan lebih dari empat gigi yaitu $3,4 \%{ }^{29}$ Salah satu penyebab perbedaan jumlah tumpatan pada setiap individu dikarenakan adanya perbedaan dalam menjaga kesehatan rongga mulut. Individu dengan kebiasaan baik menjaga kesehatan rongga mulut yaitu memperhatikan pola makan dengan menghindari makanan kariogenik dan menyikat gigi dengan waktu, metode dan teknik yang benar biasanya lebih cenderung memiliki karies yang sedikit dibandingkan individu yang kurang memperhatikan kesehatan rongga mulut.

Untuk pasien yang mendapatkan perawatan tumpatan resin komposit sejumlah dua gigi hingga lebih, terdapat tumpatan yang dilakukan hanya pada satu regio dan juga pada kedua regio. Di dalam rongga mulut pada setiap individu terdapat banyak bakteri dan kuman yang bisa menyebabkan kerusakan pada gigi, salah satunya ialah karies. Hal ini disebabkan karena pola hidup yang kurang memperhatikan kebersihan dari gigi dan rongga mulut sehingga setiap individu berpotensi terserang penyakit karies gigi.

Berdasarkan regio gigi yang ditumpat, regio posterior $(76,5 \%)$ merupakan regio yang paling banyak mendapatkan perawatan resin komposit dibandingkan pada regio gigi anterior (23,5\%). Hal ini sejalan dengan penelitian yang dilakukan di RSGMP Fakultas Kedokteran Gigi Universitas Indonesia yang menyatakan bahwa regio posterior merupakan area gigi yang lebih banyak mendapatkan perawatan restorasi gigi dibandingkan dengan regio anterior. Pada penelitian yang dilakukan oleh Sajow yang dilakukan di RSGM Universitas Sam Ratulangi Tahun 2011-2012 menyatakan bahwa berdasarkan regio gigi, tumpatan bahan resin komposit lebih banyak digunakan pada regio gigi anterior yaitu sebesar 54,1\%. Perbedaan ini disebabkan karena pada RSGM Universitas Sam Ratulangi masih menggunakan bahan tumpatan lain untuk menumpat gigi posterior sedang di poliklinik gigi RUMKITAL dr. Wahyu Slamet hanya menggunakan bahan Semen Ionomer Kaca (SIK) dan komposit sebagai bahan tumpat, SIK hanya digunakan pada gigi anterior dan pit fissure gigi posterior, sehingga penggunaan Komposit untuk regio gigi posterior lebih tinggi di bandingkan regio gigi anterior. Hal ini disebabkan oleh bentuk anatomis pit dan fissure yang dalam pada gigi posterior, sehingga memudahkan terjadinya penimbunan pencetus karies. ${ }^{16}$

\section{SIMPULAN}

Berdasarkan penelitian yang dilakukan di RUMKITAL dr. Wahyu Slamet maka dapat disimpulkan :

1 Penggunaan resin komposit pada tahun 2013 lebih banyak.

2 Kunjungan pasien laki-laki lebih banyak daripada pasien perempuan.

3 Pasien golongan umur 26-55 tahun merupakan pasien penggunaan resin komposit terbanyak.

4 Pasien kelompok pelajar paling banyak melakukan perawatan tumpatan resin komposit.

5 Pasien pada satu gigi merupakan pengguna resin komposit terbanyak.

6 Tumpatan resin komposit paling banyak dilakukan pada regio gigi posterior.

\section{SARAN}

1. Perlu dilakukan penelitian lebih lanjut mengenai gambaran tumpatan resin komposit pada instansi kesehatan lainnya yang ada di kota Bitung agar dapat dijadikan data pembanding terhadap hasil penelitian ini.

2. Bagi Poliklinik Gigi RUMKITAL dr. Wahyu Slamet, diharapkan dapat meningkatkan kinerja dalam hal pelayanan pada pasien yang datang untuk melakukan pemeriksaan dan perawatan kesehatan gigi dan mulut. 
Tulenan, Wicaksono, Soewantoro; Gambaran Tumpatan Resin Komposit...

\section{DAFTAR PUSTAKA}

1. Ruslawati Y. Diet yang dapat Merusak Gigi pada Anak-anak. Badan Penelitian dan Pengembangan Kesehatan, Departmen Kesehatan RI. Jakarta : Cermin Dunia Kedokteran, 2005 ; 73 : 45-47

2. Riset Kesehatan Dasar. Badan penelitian pengembangan kesehatan Departemen Kesehatan, Republik Indonesia. Jakarta; Laporan Nasional : 2013.h.100-104.

3. Marhaban AIA, Mariati NW, Mitjelungan C. Gambaran tumpatan status amalgam dan semen ionomer kaca pada masyarakat kelurahan Kalumpang kecamatan Ternate Tengah. Jurnal Biomedik Maret 2013;5 (1): h.158-62

4. Putriyanti F, Herda E, Soufyan A. Pengaruh saliva buatan terhadap diametral tensile strength micro fine hybrid resin composite yang direndam dalam minuman isotonic. Jurnal PDGI 2012 Jan-April ; 61(1): h.43-7.

5. Anusavice, Kenneth JP. Buku ajar ilmu bahan kedokteran gigi, Alih bahasa Johan AB, ed.10. Jakarta: EGC;2003.h.75-6,22799.

6. Baum, Lloy dkk. Buku ajar ilmu konservasi gigi, ahli bahasa, Rasinta Tarigan, ed. 3. Jakarta: EGC; 1997. h.45-8.

7. Koudi MS, Patil SB. Prep Manual for Ungraduates: Dental materials, $1^{\text {st }}$ ed. London : Mosby Elsevier. 2007 : h. 130-131

8. Sintawati J, Soemartono SH, Suharsini M. Pengaruh durasi aplikasi asam folat $37 \%$ terhadap kekuatan geser restorasi resin komposit pada email gigi. Indonesian Journal of Dentistry. 2008; 15(2):97-103.
9. Puckett AD, Fichie JG, Kirk Pc, et al. Direct composite restorative materials. Dentr Clin N Am.2007;51:p.659

10. Farahanny W. Teknik restorasi resin komposit posterior Klas II Mod. Maj Kedokteran Gigi (Dent. J) 2009; 30(2): 50-5

11. Reis AF, Giannini M, Lovadino JR, Ambrosano GM, Effect of various finishing system on the surface roughness and stanning susceptibility of packable composite resin. J dent Mater.2004

12. Dental board of california(editorial).CA Sacramento. 2005;5; p.04

13. Satish C, Chandra S, Girish C. Textbook of operative dentistry. New delhi: 2007. p.236237.

14. Strassler HE, Predictable restoration of posterior teeth with composite resin. University of Maryland Dental School;2009;p.98-104

15. Panto, Vincent. Nano hybrid komposit. (online). Tersedia:http:// repository.usu.ac.id/ handle/123456789/21456.10 April 2012

16. Indriani. Survei pemaparan penggunaan amalgam, GIC, dan resin komposit sebagai bahan tumpat gigi di RSGMP FKG UI pada tahun 2005, 2006, dan 2007. Skripsi. Jakarta: Universitas Indonesia; 2008.h.2

17. Riyadi R. Buku Ajar Ilmu kesehatan penyelaman dan hiperbarik. Buku Ajar. Surabaya: Lembaga Kesehatan Kelautan TNI AL. 2013.h.55

18. Sajow P, Rattu MJ, Wicaksono DA. Gambaran penggunaan resin komposit di Balai Pengobatan Rumah Sakit Gigi dan Mulut Universitas Sam Ratulangi tahun 2011-2012.Jurnal E Gigi.2013;6(4) 